IFN Working Paper No. 626, 2004

\title{
The Organization of the Innovation Industry: Entrepreneurs, Venture Capitalists, and Oligopolists
}

Per-Johan Norbäck and Lars Persson 


\title{
The Organization of the Innovation Industry:
}

\section{Entrepreneurs, Venture Capitalists, and Oligopolists*}

\author{
Pehr-Johan Norbäck \\ Lars Persson \\ Research Institute of Industrial Economics and CEPR
}

September 2, 2004; revised June 11, 2007

\begin{abstract}
Exit of venture-backed firms often takes place through sales to incumbents. We show that in such an environment, venture-backed firms have a stronger incentive to develop basic innovations into commercialized innovations than incumbents, due to strategic product market effects on the sales price of the venture-backed firm. This will increase the price for basic innovations, thereby triggering more innovations by entrepreneurs. Consequently, a venture capital market implies that more innovations are created, and that these become better developed. Moreover, we show that to exist in equilibrium, venture capitalist must be more efficient, otherwise incumbents will preempt venture capitalists entering the market by acquiring basic innovations.

Keywords: Acquisitions, Entrepreneurship, Innovation, Venture Capital

JEL classification: G24, L1, L2, M13, O3
\end{abstract}

${ }^{*}$ We have benefitted from useful comments from Daron Acemoglu, Ulf Jakobsson, Rachel Kranton, Kevin Murphy, Søren Bo Nielsen, Jonas Vlachos, and participants in seminars at the Research Institute of Industrial Economics (Stockholm), IGIER at Bocconi University, Helsinki Center of Economic Research, and IUI Network: Theory and Practise Workshop (Stockholm). Financial support from the Marianne and Marcus Wallenberg Foundation and Tom Hedelius' and Jan Wallander's Research Foundation is gratefully acknowledged. Email: lars.persson@ifn.se, Pehr-Johan.Norback@ifn.se. 


\section{Introduction}

There is a growing awareness of the role played by venture capitalists in the innovation process. ${ }^{1}$ Venture capitalists have come to specialize in financing early-stage investment for entrepreneurs and providing business experience. ${ }^{2}$ In a study on venture capital and innovation, Kortum and Lerner (2000) find increases in venture capital activity in an industry to be associated with significantly higher patenting rates. Moreover, Hellmann and Puri (2000) find venture capital to be associated with a significant reduction in the time required for bringing a product to the market. This raises the question of why venture-backed firms are more aggressive and more successful than incumbent firms in bringing commercialized innovations to the market.

The starting point of this paper is that the exit of the venture-backed firm often takes place through the acquisition of an incumbent firm. ${ }^{34}$ Figure 1.1 depicts the quarterly value of exits through M\&As and IPOs, respectively, in the US in the period 1999 to 2005. Note that M\&As dominate as the exit mode, except at the beginning of the period. According to the Economist $(1999)^{5}$, the exit strategy of venture capital firms changed in the late 1990's from initial public offerings (IPOs) to exit by sale: "Over the past year or so, however, venture-capital firms' exit strategy has changed. ... more and more entrepreneurs are starting enterprises with the express purpose of being bought out in due

\footnotetext{
${ }^{1}$ See, for instance, Gompers and Lerner (2001).

${ }^{2}$ Hellmann and Puri (2002) find evidence of US venture capital being related to a variety of professionalization measures, such as human resource policies, the adoption of stock options plans, and the hiring of a marketing VP. Bottazzi, Da Rin and Hellmann (2004) find similar evidence for European venture capital.

${ }^{3}$ For instance, Cochrane (2005) uses data over the period 1987 to June 2000 from the VentureOne database and shows that $20 \%$ of the ventures were acquired, $21 \%$ were IPOs, $9 \%$ went out of business, while 49\% remained private. Cumming and MacIntosh (2003) found similar figures.

${ }^{4}$ Granstrand and Sjölander (1990) present evidence from Sweden and Hall (1990) presents evidence from the US that firms acquire innovative targets to gain access to their technologies. In the biotech industry, Lerner and Merges (1998) note that acquisitions are important for knowhow transfers. OECD (2002) argues that established firms often acquire firms to access new technologies.

5 "Easy way out", Feb 18 1999, The Economist.
} 


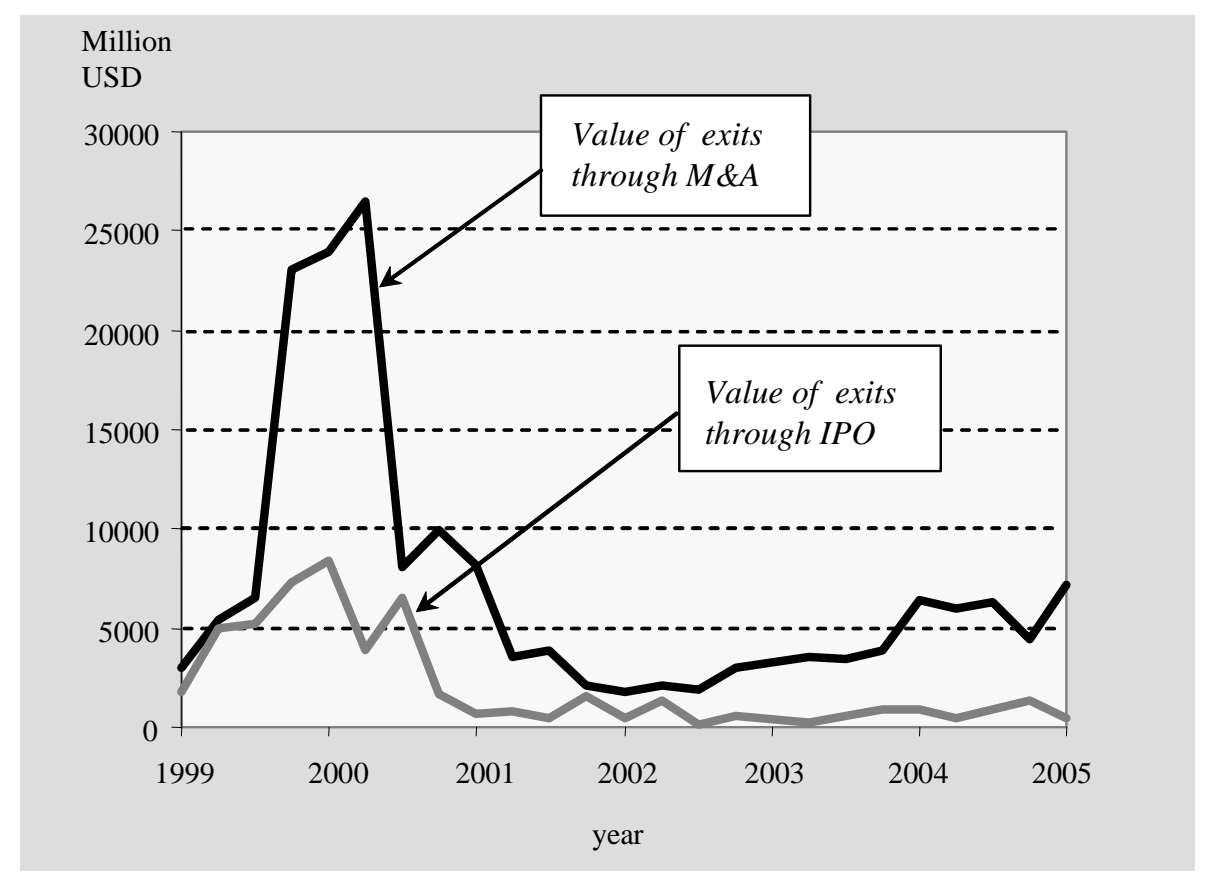

Figure 1.1: The value of exits through M\&A and IPO in the US. Source: Thomson Venture Economics/National Venture Capital Association.

course." Moreover, according to the Economist (1999), innovators know that incumbent firms in highly concentrated markets are those willing to pay the most for innovations, as indicated by the following quote: "Companies like Cisco, Intel and Microsoft recognize the threat posed by nimble young firms getting technologies to market at unimaginable speeds," says Red Herring's Brian Taptich. "And they're willing to pay extremely high premiums to protect their franchises." 6

In the literature, informational advantages and abilities have been suggested to explain why venture capitalists are more aggressive and more successful in creating commercialized innovations. ${ }^{7}$ We add to this literature by showing that venture-backed firms selling innovations to incumbents in concentrated markets have a stronger incentive to develop basic innovations into commercialized innovations than incumbent firms, due to strategic

\footnotetext{
${ }^{6}$ An example is Cerent, which was acquired by Cisco at $\$ 6.9$ billion.

${ }^{7}$ See, for instance, Gompers and Lerner (2001) for an overview of the empirical literature and see, for instance, Keuschnigg and Nielsen (2004) for a theoretical contribution.
} 
product market effects on the sales price of the innovation. In turn, this will increase the price of basic innovations, thereby triggering a larger number of such innovations by entrepreneurs. Consequently, the presence of a venture capital market implies that more basic innovations are created and better developed.

We present a model where a market is served by several incumbent firms competing in oligopoly fashion. In the initial stage of the interaction, there is an entrepreneur investing in an innovative activity that might lead to the creation of a basic innovation, which is novel but requires additional development for commercial use. But the entrepreneur cannot develop the basic innovation herself and, in a second stage, she may sell it to one of the incumbent firms. Alternatively, the entrepreneur can seek support from one among several venture capitalists competing to provide expertise and financial support to develop the basic innovation. We model the sale of the basic innovation as a first-price perfect information auction, where incumbent firms and venture capitalists bid for the basic innovation. ${ }^{8}$ If the entrepreneur "sells" the basic innovation to a venture capitalist, the venture-backed firm invests in the development of the innovation, which will increase the possessor's profit, but decrease the profits of the rival incumbent firms in the product market. The venture-backed firm will then exit by selling the developed innovation at a first-price perfect information auction, where the incumbent firms are the potential buyers. If, on the other hand, an incumbent firm obtains the basic innovation directly in the initial stage, the acquiring firm invests in development. Given the innovation and development pattern, the incumbent firms compete in oligopoly fashion in the product market, in the final stage.

We first show that a venture-backed firm has an incentive to develop the basic innovation further than an incumbent firm, due to strategic product market effects. ${ }^{9}$ The reason

\footnotetext{
${ }^{8}$ All players in the model are completely informed about their own and other players' characteristics. This allows us to clearly attribute market force effects, as opposed to, say, problems of incomplete information, which have been extensively studied in the literature (see Gompers and Lerner (2001) for an overview).

${ }^{9}$ Hellmann and Puri (2000) provide empirical evidence of venture capital financing being
} 
is that an incumbent firm only takes into account how its own profit increases when investing in development. The venture-backed firm, in contrast, takes into account how the acquisition price of the developed innovation is affected. In equilibrium, the acquisition price is shown to equal an incumbent firm's valuation of obtaining the developed innovation which, in turn, consists of the profit for this firm of obtaining the developed innovation net its profit, if it is obtained by a rival firm. The venture capitalist thus internalizes that investments in the development of the basic innovation increase in the acquisition price, not only by generating an increase in the acquirer's profit, but also through the negative impact on the non-acquirer's profit (due to the development of more competitive assets).

We then examine how the presence of a venture capital market affects entrepreneurs' incentives to innovate. In the policy debate, it has been argued that a well-functioning venture capital market will increase the innovative activity in the industry, thereby contributing to the economic growth of a country. ${ }^{10}$ In line with this view, we show that the entrepreneurial effort to innovate is higher when venture capitalists support entrepreneurs to develop their basic innovations into developed innovations, as compared to a case where the incumbent directly acquires basic innovations. The reason is that a venture-backed firm maximizes the net acquisition price when determining the development level, which implies that it obtains a net acquisition price equal to an incumbent firm's maximum valuation of a developed innovation. Bidding competition among venture capitalists for such an opportunity then bestows the entrepreneur with a higher reward for successful innovation which, in turn, induces a higher entrepreneurial effort to innovate.

A further result derived is that when venture capitalists and incumbent firms are equally efficient in developing basic innovations and compete to gain control over these, preemptive acquisitions by incumbents occur. Incumbent firms then take into account that venture-backed firms will invest more aggressively in development and thus preempt such, for them, excessive investments in development. However, this implies that to exist in related to product market strategies and outcomes of start-ups.

${ }^{10}$ See, for instance, OECD (1999) and European Commission (1999). 
equilibrium, venture capitalist must be substantially more efficient, otherwise incumbents will preempt venture capitalists entering the market by acquiring basic innovations.

This paper can be then seen as a contribution to the literature that studies the properties of the innovation market when innovations can be developed both by incumbents and independent parties. One strand of this literature takes the starting point in that development by incumbents are associated with synergies with existing assets, but are at the same associated with less powered incentive schemes. In such an environment, Amador and Landier (2003) studies how the level of potential of the project affects the pattern of independent and incumbent-based development, Anand, Gatetovic and Stein (2004) studies how the pattern of independent and incumbent-based development is affected by changes of property rights, and Gromb and Scarfstein (2002) make use of a labor market model to determine the equilibrium level of independent and incumbent-based development. Another strand of this literature studies how product market effects affects the pattern of independent and incumbent-based development of innovations. Hellmann (2002) studies how the level of complementarity and substitutability between an innovation and an oligopolistic incumbent's assets affects independent and incumbent-based financing. Anton and Yao (1994) studies how the competing threats of expropriation by the incumbent and product market entry by the independent innovator affects the division of surplus from the innovation, and Gans and Stern (2000) extend this approach to study how these forces affects the R\&D incentive pattern of incumbents and independent innovators.

We add to the above literature by endogenizing the productivity (size) of the innovation and allow for competitive bidding among the oligopolistic incumbents over the innovation. It is then shown that due to the difference in incentives between the selling independent developer and the incumbent (the former maximizes the net sales price and the latter maximizes net profits), the selling independent developer has an incentive to choose a higher level of productivity of the assets than the incumbent's optimal choice.

This paper is also related to the literature on patent licensing, where licences are sold 
to potential buyers that are competing in a downstream oligopoly market. ${ }^{1112}$ Most papers in this literature treat the size of the innovation as exogenous. To our knowledge, the only exception is Katz and Shapiro (1986) who determine the optimal licensing fee of a research lab which can affect the size of the innovation. They find that the incentive to develop the innovation is decreasing in the number of incumbents owning the research lab. We add to this literature by endogenously determining the ownership of the innovation - before and after its size (or development) is determined - in situations where agents with different characteristics are potential owners.

Finally, this paper can also be seen as a contribution to the literature on entrepreneurship and innovations. ${ }^{13}$ We extend this literature by constructing a theoretical model framework where efficiency effects of the interaction between entrepreneurs, venture capitalists and oligopolist in the innovation process can be analyzed; ${ }^{14}$ an interaction which in the policy debate has been argued to be of great importance for the functioning of the innovation industry.

The model is spelled out in Section 2. In Section 3, we explore how the incentives to develop basic innovations differ between venture-backed and incumbent firms. In Section 4, we determine the ownership pattern of basic innovations and study the effects of venture capital on the incentive for basic innovations. In Section 5, we study how efficiency differences between venture capitalists and incumbents affect the equilibrium organization of the innovation industry. In Section 6, we explore effects of allowing for simultaneous

\footnotetext{
${ }^{11}$ For an overview, see Kamien (1992). The paper is also related to the literature on the persistence of monopoly; see, for instance, Chen (2000) and Gilbert and Newbery (1982).

12 This paper could also be seen as a contribution to the literature on auctions with externalities. See, for instance, Jehiel, Moldovanu and Stacchetti (1999) and Jehiel and Moldovanu (2000). We add to this literature by endogenizing the productivity of the assets sold in an environment where this productivity can be affected by an ex ante investment of the seller.

${ }^{13}$ For overviews, see Acs and Audretsch (2005), and Bianchi and Henrekson (2005).

${ }^{14}$ Baumol (2004) stresses the importance of the different roles played by small entrepreneurial firms and large established firms in the innovation process in the USA, where small entrepreneurial firms create a large share of breakthrough innovations and large established firms provide more routinized $\mathrm{R} \& \mathrm{D}$.
} 
investment by the entrepreneur and the venture capitalist, and effects of allowing the incumbents to be asymmetric. In Section 7 empirical implications of the model are discussed. Section 8 concludes.

\section{The Model}

The model is illustrated in Figure 2.1. We consider an oligopoly industry served by a set $i \in \mathcal{I}$ of symmetric incumbent firms, where $\mathcal{I}=\left\{1,2, . ., i, \ldots, N_{I}\right\}$. There is also an entrepreneur, denoted $E$, which in stage zero invests in a research effort $e$ that could lead to the creation of a unique productive asset, referred to as the basic innovation. If successful, this entrepreneur can sell the basic innovation to one of the incumbent firms in stage 1. Alternatively, the entrepreneur can seek support from a venture capitalist providing expertise and financial support to develop the basic innovation. Without this support, the entrepreneur cannot develop her basic innovation. Consequently, the role played by venture capital is to make it possible for the entrepreneur to develop her basic innovation into an asset ready for commercialized use. The entrepreneur may then choose from a set $j \in \mathcal{J}$ of symmetric venture capitalists, where $\mathcal{J}=\left\{1,2, . ., j, . ., N_{J}\right\}$. The venture capitalists compete to provide expertise and financial support to the entrepreneur in return for equity holdings in the firm. To focus on product market effects as a determinant of the ownership of the basic innovation, we model the sale of the basic innovation as a first-price perfect information auction with incumbent firms and venture capitalists bidding for the innovation.

If the entrepreneur obtains financing and support from a venture capitalist $j$ in stage 1 , the venture-backed firm can, in stage 2 , invest $k_{V_{j}}$ in the development of the basic innovation, thereby creating a developed innovation where further development will increase the possessor's profit, but decrease the profits of the rival incumbent firms in the ensuing product market. Note that ex-ante symmetry implies $k_{V}=k_{V_{j}}$. If, on the other

hand, an incumbent firm $i$ obtains the innovation in stage 1, the acquiring firm invests 
$k_{A_{i}}$ in development in stage 2 where again ex-ante symmetry implies $k_{A}=k_{A_{i}}$. In stage 3 , upon development, the venture-backed firm $j$ exits by selling the developed innovation at a first-price perfect information auction, where the $N_{I}$ incumbent firms are the potential buyers of the developed innovation. ${ }^{15}$ Finally, in stage 4 , the incumbent firms compete in oligopoly interaction, setting an action $x_{i}$.

\section{Venture capitalists and the incentives to develop innovations}

Let us first examine how the incentives of venture-backed firms and incumbent firms to develop the basic innovation differ. To highlight the product market effects on innovations and the presence of venture capital, we shall initially assume that incumbent firms and venture capitalists will only differ in objectives, but are otherwise symmetric in all other dimensions. Other asymmetries between these agents will be introduced in sections 5 and 6

\subsection{Stage 4: Product-market equilibrium}

Using backward induction, we start with the product market interaction, where firm $i$ chooses an action $x_{i} \in R^{+}$to maximize its direct product market profit, $\Pi_{i}\left(x_{i}, \mathbf{x}_{-i}, k\right)$, which depends on its own and its rivals' market actions, $x_{i}$ and $\mathbf{x}_{-i}$ (which is the $\left(N_{I}-\right.$ 1) $\times 1$ vector of actions taken by rival incumbent firms), as well as the total amount of development undertaken (by the acquiring incumbent or the venture-backed firm) $k$, where we in order to avoid heavy notation omit the subindex. We may consider the action $x_{i}$ as setting a quantity or a price, as will be shown in later sections. We assume that there exists a unique Nash-Equilibrium in actions, $\mathbf{x}^{*}(k)$, defined from the first-order condition $(3.1)$ :

\footnotetext{
${ }^{15}$ It is shown in Norbäck and Persson (2006) that the acquiring firm will never invest sequentially in equilibrium.
} 


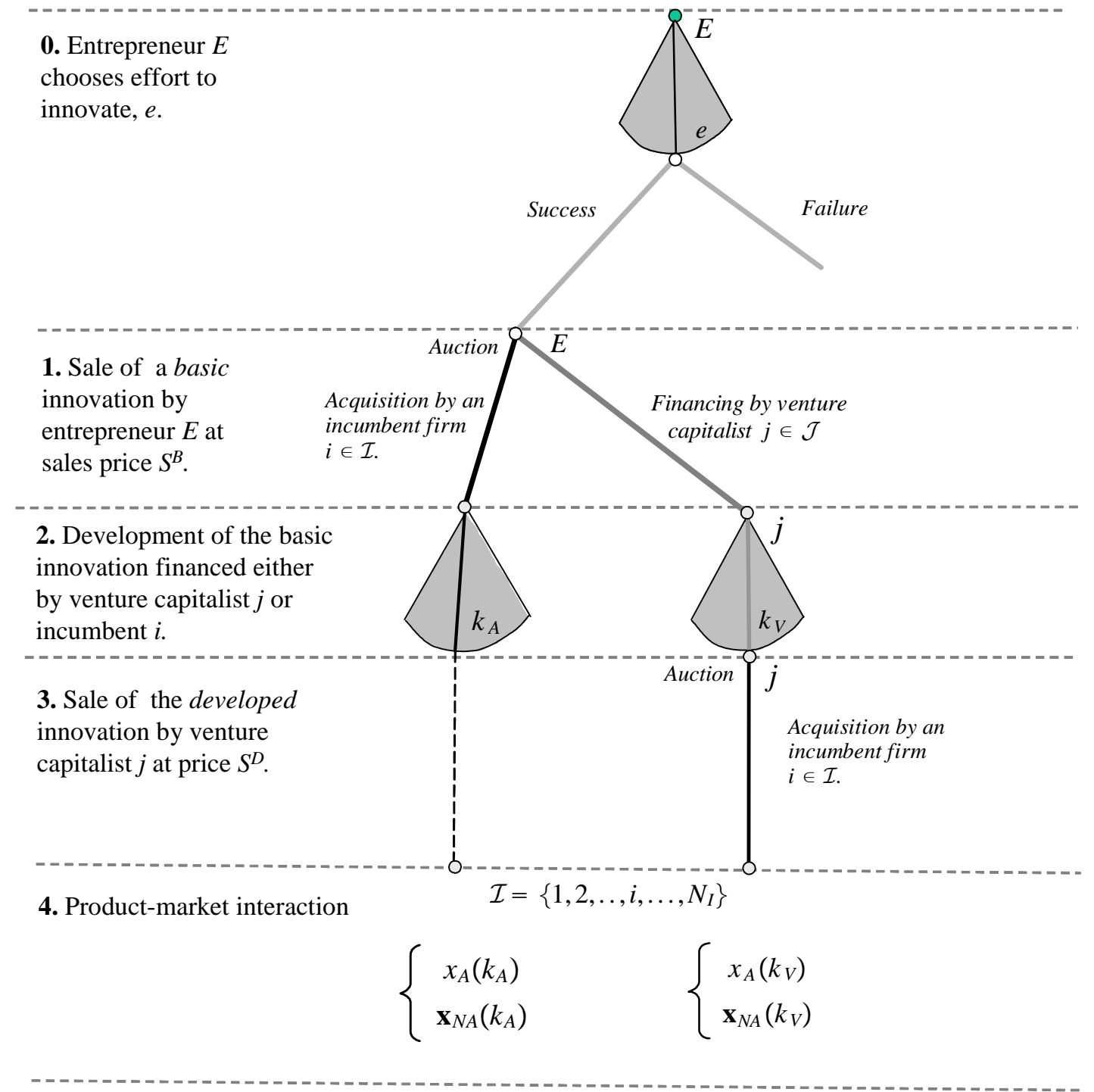

Figure 2.1: The structure of the game. 


$$
\frac{\partial \prod_{i}}{\partial x_{i}}\left(x_{i}^{*}, \mathbf{x}_{-i}^{*} ; k\right)=0,
$$

where $\mathbf{x}_{-i}^{*}$ is the actions by firm $i$ : s rivals.

Using the ex-ante symmetry among incumbent firms, we only need to distinguish between two firm types, i.e. the acquiring firm (denoted $A$ ) and the non-acquiring firms (denoted $N A$ ). The actions are then simply $x_{A}=x_{A_{i}}$ and $x_{N A}=x_{-N A_{i}}$, where $x_{N A}$ is one of the $\left(N_{I}-1\right) \times 1$ arguments in the vector $\mathbf{x}_{N A}$ of symmetric actions taken by non-acquiring incumbent firms. Since the optimal actions for the acquirer $\left(x_{A}^{*}\right)$ and the non-acquirers $\left(\mathbf{x}_{N A}^{*}\right)$, respectively, only depend on $k$, we can define the reduced-form product market profits of the acquirer and a non-acquirer as direct functions of $k:^{16}$

$$
R_{A}(k) \equiv \Pi_{A}\left(x_{A}^{*}(k), \mathbf{x}_{N A}^{*}(k), k\right), \quad R_{N A}(k) \equiv \Pi_{N A}\left(\mathbf{x}_{N A}^{*}(k), x_{A}^{*}(k)\right) .
$$

We shall assume the reduced-form product market profit for a firm of type $h=\{A, N A\}$, $R_{h}(k)$, to have the following characteristics:

Assumption 1: $\frac{d R_{A}}{d k}>0$ and $\frac{d R_{N A}}{d k}<0$

Assumption 1 states that the reduced-form product market profit for the acquirer is strictly increasing in investments for development in the innovation, whereas such investments strictly decrease the rivals' profits. To keep the exposition simple, we use the derivatives of reduced-form product market profits in Assumption 1, $\frac{\partial R_{A}}{\partial k}$ and $\frac{\partial R_{N A}}{\partial k}$, keeping in mind that these summarize the total effects on the product-market profits. ${ }^{17}$

\subsection{Stage 3: Sale of the developed innovation by the venture-backed firm}

We model the acquisition process in stage 3 as a perfect information auction where the $N_{I}$ incumbent firms simultaneously post bids, which are then accepted or rejected by the

\footnotetext{
${ }^{16}$ To save space, we write the arguments in $R_{N A}(k) \equiv \Pi_{N A}\left(\mathbf{x}_{N A}^{*}(k), x_{A}^{*}(k)\right)$ with a slight abuse of notation. Note that $R_{N A}(k)=\Pi_{N A}(x_{N A}^{*}(k), \underbrace{x_{N A}^{*}(k), \ldots ., x_{N A}^{*}(k)}_{N-2}, x_{A}^{*}(k))$.

17 Assumption 1 holds in the Linear-Quadratic Cournot model which is presented below, but it is also compatible with other oligopoly models: Farrell and Shapiro (1996).
} 
venture capitalist. Each incumbent firm announces a bid, $b_{i}$, for the developed innovation, where $\mathbf{b}=\left(b_{1}, \ldots, b_{i}, \ldots b_{N_{I}}\right) \in R^{N_{I}}$ is the vector of these bids. Following the announcement of $\mathbf{b}$, the developed innovation may be sold to one of the incumbents at the bid price, or remain in the ownership of the venture-backed firm. ${ }^{18}$ The equilibrium acquisition price is denoted by $S^{D}$.

We now turn to incumbent firms' valuations of obtaining the developed innovation $w_{I I}$, defined in (3.3). The first term shows the profit for an incumbent firm when possessing the innovation, the second term shows the profit if it is obtained by a rival incumbent firm:

$$
w_{I I}=R_{A}(k)-R_{N A}(k)
$$

Note that since incumbent firms are symmetric ex-ante, their valuations are symmetric. It is then straightforward to derive the following lemma ${ }^{19}$ :

Lemma 1. In stage 3, the developed innovation is acquired by an incumbent firm, at a price, $S^{D}$, equal to a rival incumbent firm's valuation of the developed innovation, i.e. $S^{D^{*}}=w_{I I}$.

Proof. See Appendix A.1.

\subsection{Stage 2: Development of the basic innovation}

In subsection 3.3.1 we determine the optimal level of development when an incumbent develops the basic innovation, whereas Section 3.3.2 determines the optimal level of development when the venture backed firm develops the basic innovation.

\footnotetext{
${ }^{18}$ If more than one of the incumbent firms make such a bid, each such firm obtains the assets with equal probability. The acquisition is solved for Nash equilibria in undominated pure strategies. There is a smallest amount, $\varepsilon$, chosen such that all inequalities are preserved if $\varepsilon$ is added or subtracted.

19 The correct acquisition price is $w_{I I}-\varepsilon$, but to simplify the presentation, we use $w_{I I}$.
} 


\subsubsection{The acquiring incumbent's optimal development}

Assume that the acquirer faces a strictly convex investment function, $C(k)$, such that $C^{\prime}(k)>0$ and $C^{\prime \prime}(k)>0$. Then, the maximization problem facing the acquiring incumbent firm can be written as follows:

$$
\underset{\{k\}}{\operatorname{Max}}: R_{A}(k)-C(k)
$$

where $C(k)=\int_{0}^{k} C^{\prime}(k) d k$ is the total cost of investing $k$ in development, and $C^{\prime}(k)$ is the associated marginal cost.

We assume $R_{A}(k)-C(k)$ to be strictly concave in $k$. The optimal choice by the acquiring firm is then defined from the unconstrained optimum condition (3.5):

$$
\frac{d R_{A}}{d k}=C^{\prime}\left(k_{A}^{*}\right)
$$

where $k_{A}^{*}$ is illustrated in point $A$ in Figure 3.1(i).

\subsubsection{The venture backed firm's optimal development}

The venture-backed firm invests in development of the basic innovation maximizing the net sales price of a developed innovation, i.e., $S^{D}(k)-C(k)$. To focus on the product market effects, we assume the venture-backed firm and the incumbent firms to face the same variable cost function $C(k)$ when investing in development. Using Lemma 1 and (3.3), this problem is then defined as:

$$
\begin{array}{ll} 
& \underset{\{k\}}{\operatorname{Max}}: S^{D}(k)-C(k) \\
\text { s.t }: & S^{D}(k)=R_{A}(k)-R_{N A}(k)
\end{array}
$$

The first-order condition, is:

$$
\frac{d S^{D}}{d k}=\frac{d R_{A}}{d k}-\frac{d R_{N A}}{d k}=C^{\prime}\left(k_{V}^{*}\right):
$$

where we assume that $R_{A}(k)-R_{N A}(k)-C(k)$ is strictly concave in $k$. The optimal $k$ is indicated as $k_{V}^{*}$ in Figure 3.1(i). Comparing expressions (3.5) and (3.7), we see that 


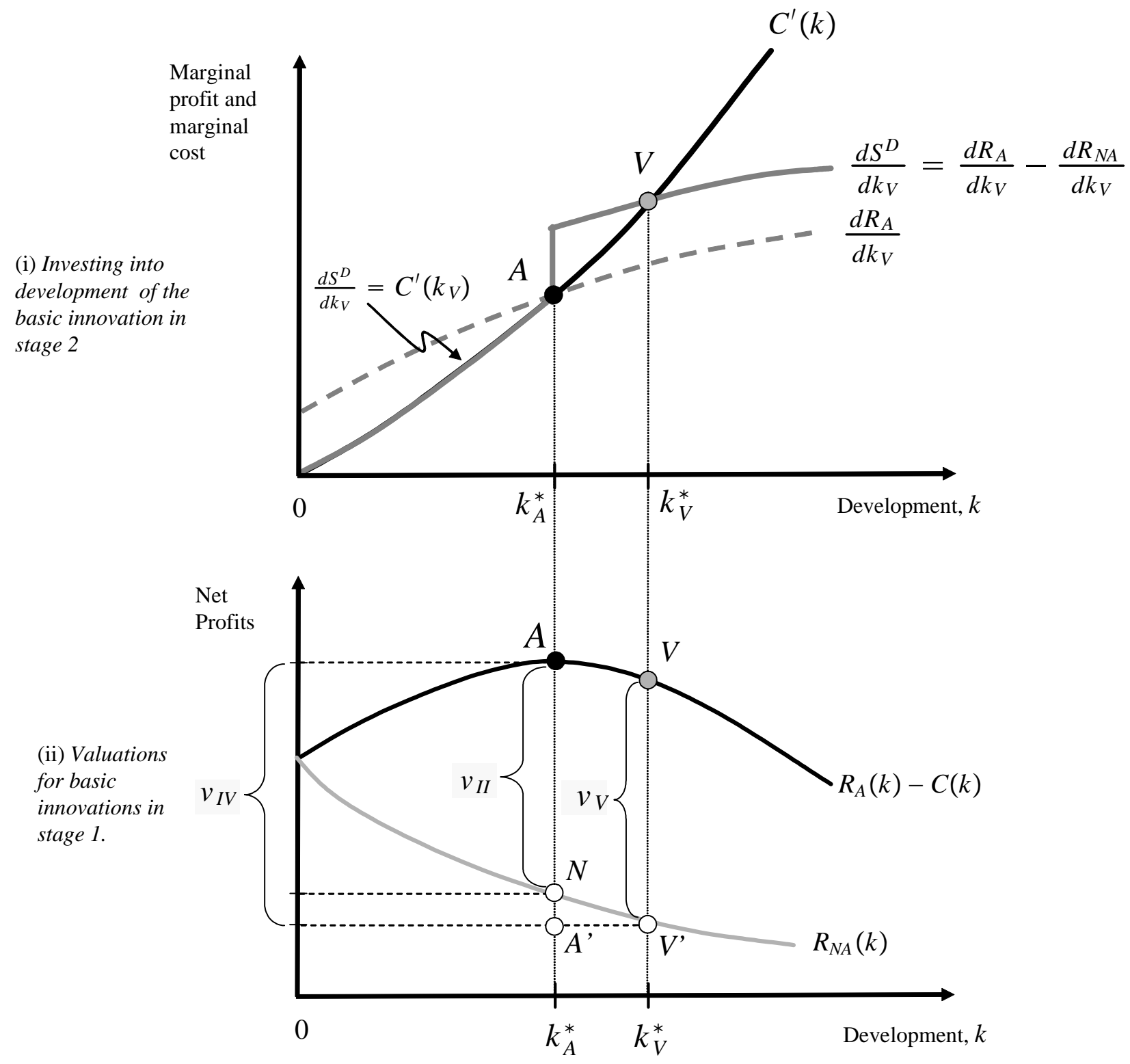

Figure 3.1: Investment incentives and the valuations for basic innovations 
the venture capitalist has stronger incentives to invest in development than the acquiring firm, since the venture capitalist achieves a higher acquisition price by not only taking into account the increase in profits for the acquirer $\frac{d R_{A}}{d k}$, but also by exploiting the negative externalities on the non-acquirer, captured by the last term $\frac{d R_{N A}}{d k}$, which is negative from Assumption 1.20

We have thereby derived the following result:

Proposition 1. (i) The optimal level of development by a venture-backed firm which sells the developed innovation to an incumbent firm exceeds the optimal level of development by the acquiring incumbent firm, i.e. $k_{V}^{*}>k_{A}^{*}$.

Thus, proposition 1 shows that a venture capitalist has a stronger incentive to develop an innovation than an incumbent firm, since it internalizes the negative effect of development on the non-acquiring firm's profit through the higher acquisition price.

\section{The equilibrium ownership of basic innovations and the entre- preneurs' incentives to innovate}

We now turn to the question of how the presence of venture capitalists affects the entrepreneur's efforts to produce innovations in stage 0 . Once more, we focus on product-market forces as the determinants of the equilibrium innovation pattern by assuming that the entrepreneur sells the basic innovation to the highest bidder at an auction in stage 1 . We apply the same acquisition process as in section 3.2 and refer to the description of the game provided in that section. In the auction, incumbent firms' bids are interpreted as direct payments for a full acquisition, while venture capitalists' bids are interpreted as offers of finance and support, in return for a stake in the proceeds of the sale of the developed innovation in stage 3 . To simplify, we assume the venture capitalist to obtain the total

\footnotetext{
${ }^{20}$ For $k_{V}<k_{A}^{*}$, the increase in sales price only reflects avoided development costs, i.e. $\frac{d S^{D}}{d k_{V}}=C^{\prime}\left(k_{V}\right)$. See Norbäck and Persson (2006).
} 
proceeds of the sale of the venture-backed firm in stage 3. We relax this assumption in Section 6.1.

\subsection{Stage 1: The equilibrium ownership of basic innovations}

To distinguish stage 1 valuations from stage 3 valuations $w$, we denote the former by $v$. We now derive and rank these stage 1 valuations in order to solve for the equilibrium ownership and acquisition price for the basic innovation.

First, the valuation $v_{I I}$ is the value for an incumbent firm of acquiring the basic innovation, when it would otherwise be obtained by a rival incumbent:

$$
v_{I I}=R_{A}\left(k_{A}^{*}\right)-C\left(k_{A}^{*}\right)-R_{N A}\left(k_{A}^{*}\right) .
$$

Thus, $v_{I I}$ is the difference in the net profit $R_{A}(k)-C(k)$ of the acquirer and the profit of the non-acquirer $R_{N A}(k)$, evaluated at the acquiring incumbents optimal development, $k_{A}^{*}$ from (3.5). $v_{I I}$ is given as the vertical distance between points $\mathrm{A}$ and $\mathrm{N}$ in Figure ??(ii).

Second, a venture capitalist's stage 1 valuation of the basic innovation, denoted $v_{V}$, is the sales price of the developed innovation in stage 3 , net the investment costs. From Lemma 1, we have $S^{D^{*}}=w_{I I}\left(k_{V}^{*}\right)=R_{A}\left(k_{V}^{*}\right)-R_{N A}\left(k_{V}^{*}\right)$, and thus the venture capitalist's valuation of the entrepreneur's basic innovation is:

$$
\begin{aligned}
v_{V} & =S^{D^{*}}-C\left(k_{V}^{*}\right) \\
& =R_{A}\left(k_{V}^{*}\right)-R_{N A}\left(k_{V}^{*}\right)-C\left(k_{V}^{*}\right),
\end{aligned}
$$

Since a venture capitalist maximizes the net value of incumbent firms' valuations of the innovation $R_{A}(k)-C(k)-R_{N A}(k)$, the valuation of a venture capitalist must exceed that of an incumbent firm, when it considers that a rival incumbent would otherwise obtain the innovation, $v_{V}>v_{I I}$. This is illustrated in Figure 3.1(ii), where $v_{V}$ is shown as the vertical distance between $\mathrm{V}$ and $\mathrm{V}$ '.

However, as noted in Figure 3.1(i), if a venture capitalist does obtain the basic innovation, it will be more aggressively developed, $k_{V}^{*}>k_{A}^{*}$. This implies that the profit 
for an incumbent firm of not obtaining the innovation under a venture ownership of the basic innovation, $R_{N A}\left(k_{V}^{*}\right)$, will be lower than from the corresponding one when a rival incumbent owns the basic innovation, $R_{N A}\left(k_{A}^{*}\right)$. Therefore, there is a third valuation to consider, $v_{I V}$, which is the value for an incumbent firm of obtaining the innovation when it would otherwise be obtained by a venture capitalist:

$$
v_{I V}=R_{A}\left(k_{A}^{*}\right)-C\left(k_{A}^{*}\right)-R_{N A}\left(k_{V}^{*}\right)
$$

The valuation $v_{I V}$ is also shown in Figure 3.1(ii). As the figure illustrates, an incumbent is willing to pay more than a venture capitalist to obtain the innovation, in order to avoid the overinvestment by the venture capitalist, $v_{I V}>v_{V}$. This follows from $v_{I V}-v_{V}=R_{A}\left(k_{A}^{*}\right)-$ $C\left(k_{A}^{*}\right)-\left[R_{A}\left(k_{V}^{*}\right)-C\left(k_{V}^{*}\right)\right]>0$ since $k_{A}^{*}<k_{V}^{*}$ maximizes the acquiring incumbents' net profits $R_{A}(k)-C(k)$.

Thus, we have established the following ranking of valuations:

$$
v_{I V}>v_{V}>v_{I I}
$$

Using (4.4) we can derive the equilibrium ownership of the basic innovation. It can then be shown that the unique Nash equilibrium is the one where one of the incumbents acquires the basic innovation at a price $S^{B^{*}}=v_{V}$. To see this, first note that bidding competition among the symmetric venture capitalists implies that the equilibrium price cannot be lower than $S^{B}=v_{V}$. Also, note that no venture capitalist has an incentive to bid higher. Let us now consider the equilibrium candidate where one incumbent bid $v_{V}$ and the second highest bid is by an venture capitalist who bids $v_{v}-\varepsilon$. Note that the acquiring incumbent will not deviate to a lower bid since it benefits from an acquisition at $S^{B}=v_{V}$ by avoiding the excessive investments by venture capitalists which otherwise would occur. This follows from that the acquiring incumbents net profit $\pi_{A}^{*}=R_{A}\left(k_{A}^{*}\right)-C\left(k_{A}^{*}\right)-v_{V}=$ $v_{I V}-v_{V}+R_{N A}\left(k_{V}^{*}\right)>R_{N A}\left(k_{V}^{*}\right)$ by (4.4). Clearly, deviating to a higher bid is not profitable for the winning incumbent. Moreover, other incumbents will not challenge an acquisition by a rival firm since they benefit from weaker market competition, while not bearing the 
cost of the acquisition. This follows from the fact that $R_{N A}\left(k_{A}^{*}\right)=R_{A}\left(k_{A}^{*}\right)-C\left(k_{A}^{*}\right)-v_{I I}>$ $R_{A}\left(k_{A}^{*}\right)-C\left(k_{A}^{*}\right)-v_{V}=\pi_{A}^{*}$ holds by (4.4). Thus, both the acquirer and non-acquirer benefits from the preemptive acquisition, but the non-acquirers benefits more, i.e.

$$
R_{N A}\left(k_{A}^{*}\right)>\pi_{A}^{*}>R_{N A}\left(k_{V}^{*}\right)
$$

In terms of Figure 3.1(ii), the net profit of the acquirer $\pi_{A}^{*}=R_{A}\left(k_{A}^{*}\right)-C\left(k_{A}^{*}\right)-v_{V}$ will be at some point strictly between $\mathrm{A}^{\prime}$ and $\mathrm{N}$, which is strictly higher than the net profit $R_{N A}\left(k_{V}^{*}\right)$ obtained under venture-backed development at point $\mathrm{V}$ ', but be strictly lower than the profit obtained by a non-acquirer in point $\mathrm{N}, R_{N A}\left(k_{A}^{*}\right)$.

Consequently, we have derived the following result: ${ }^{21}$

Proposition 2. In stage 1, the basic innovation is acquired by an incumbent firm at a price equal to a venture capitalist's valuation, $S^{B^{*}}=v_{V}$.

Thus, the basic innovation is acquired by an incumbent firm investing $k_{A}^{*}$ in development, thereby inducing an acquisition price $S^{B^{*}}=v_{V}$. This, leads to the following corollary:

Corollary 1. Incumbents acquire basic innovations to preempt, for them, excessive investments in development that would otherwise be undertaken by venture-backed firms.

\subsection{Stage 0: Equilibrium innovation by the entrepreneur}

In stage 0, entrepreneur $E$ undertakes an effort, $e$, to discover an innovation. Let innovation costs $y(e)$ be an increasing convex function in effort, i.e. $y^{\prime}(z)>0$, and $y^{\prime \prime}(z)>0$. Let the probability of making an innovation be $z$ and the probability of a failure $1-z$, where $z \in[0,1]$ and the probability $z$ is an increasing concave function of effort, i.e. $z^{\prime}(e)>0$ and $z^{\prime \prime}(e)<0 . \pi_{E}=z(e) S^{B^{*}}-y(e)$ is then the expected net profit of undertaking effort for the entrepreneur, where $S^{B^{*}}$ is the acquisition price obtained in the auction for the basic

\footnotetext{
${ }^{21}$ Norbäck and Persson (2006) provides a detailed proof.
} 
innovation in stage 1 . The entrepreneur then maximizes $\pi_{E}$, optimally choosing effort $e$. The optimal effort $e^{*}$ is given from:

$$
\frac{d \pi_{E}}{d e}=z^{\prime}(e) S^{B^{*}}-y^{\prime}(e)=0
$$

with the associated second-order condition, $\frac{d^{2} \pi_{E}}{d e^{2}}=z^{\prime \prime}(e)-y^{\prime \prime}(e)<0$.

Applying the implicit function theorem in (4.6), we can state the following Lemma:

Lemma 2. The equilibrium innovative effort by the entrepreneur in stage $0, e^{*}$ and hence, the probability of a successful innovation $z$, increase in the acquisition price obtained in stage $1, S^{B^{*}}$, i.e. $\frac{d e^{*}}{d S^{B^{*}}}>0$.

Having established that entrepreneurial effort in stage 0 is an increasing function of the acquisition price obtained in stage 1 , we can now proceed to examine the link between the presence of a venture capitalist market and innovations by entrepreneurs.

As shown in Corollary 1, preemptive acquisitions by incumbents occur in stage 1 to preempt such, for them, excessive investments in development by venture capitalists. However, to obtain the entrepreneur's innovation, the acquiring incumbent firm must at least pay the entrepreneur a price for the innovation matching the venture-backed firm's valuation $v_{V}$, which from Proposition 2 exceeds the prevailing price if only incumbents were to bid $v_{I I}$. Then, by using Lemma 2, we can state the following Proposition:

Proposition 3. The presence of venture capitalists increases the acquisition price for basic innovations also in situations where they do not acquire basic innovations. Thus, the presence of venture capitalists increases the level of innovations.

\section{Efficiency differences between venture capitalists and incum- bents}

In this section, we study how efficiency differences between venture capital firms and incumbent firms affect the equilibrium organization of the innovation industry and thereby the equilibrium innovation and development pattern. 


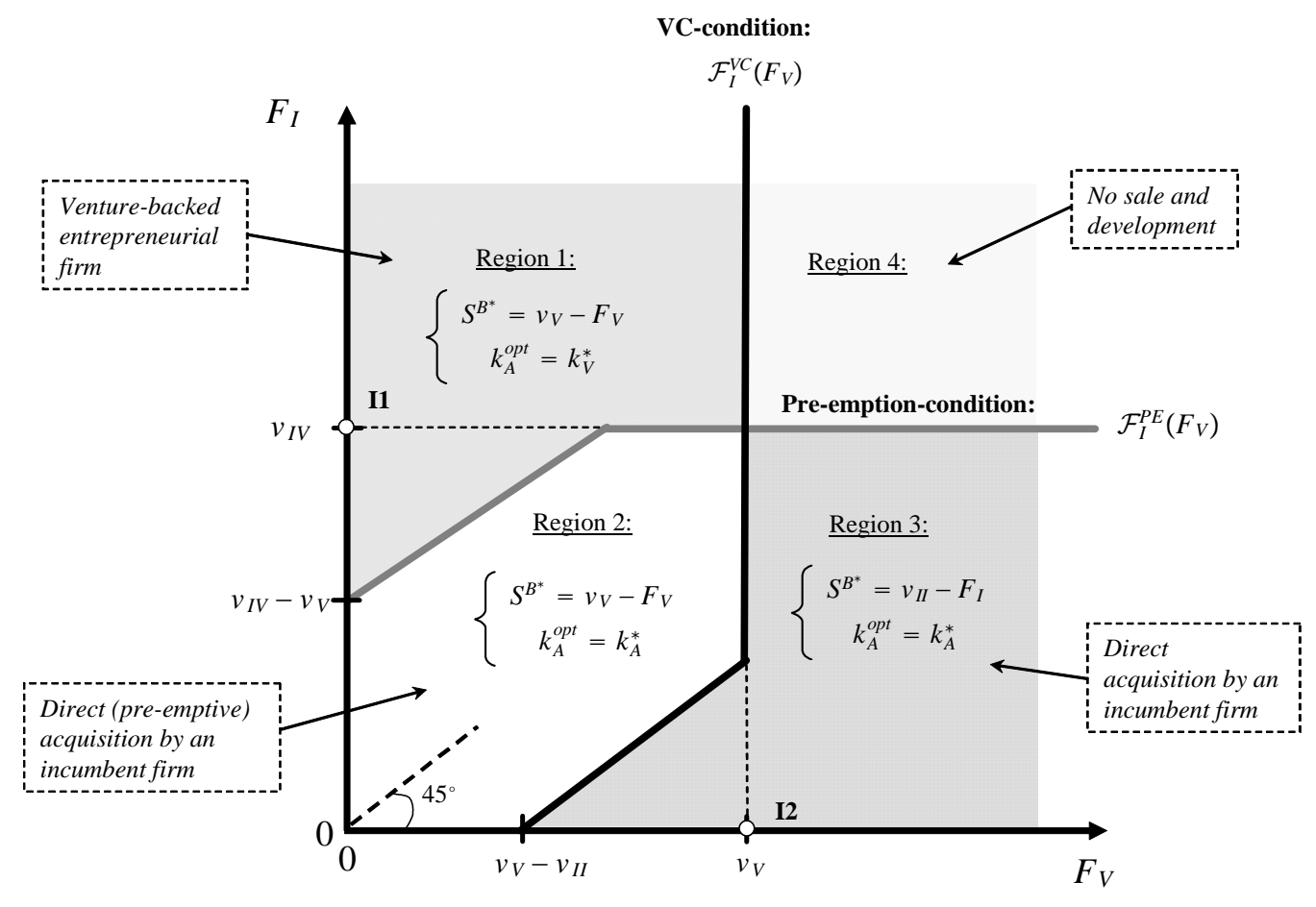

Figure 5.1: The Equilibrium Ownership Structure with fixed cost assymetries.

Empirical research on venture capitalists suggests that they possess unique assets in terms of informational advantages, monitoring and control abilities. For instance, Hellmann and Puri (2002) find evidence of US venture capital being related to a variety of professionalizing measures, such as human resource policies, the adoption of stock options plans, and the hiring of a marketing VP. Bottazzi, Da Rin and Hellmann (2004) find similar evidence for European venture capital. Yet, in other situations, incumbent firms will possess advantages due to their larger scale and accumulated knowledge. We capture such efficiency differences in a simple way by assuming venture capitalists and incumbents to differ in fixed costs $F_{h}$ associated with development, while keeping the assumption that variable costs $C(k)$ are symmetric.

The valuations will now depend on the fixed cost of development for incumbents and venture-backed firms. First, note that fixed costs must be constrained to $F_{I} \in\left[0, v_{I V}\right]$ to have incumbents bidding, and $F_{V} \in\left[0, v_{V}\right]$ to have venture capitalists bidding, where $v_{I V}$ 
and $v_{V}$ are defined in Section 4.1. For such low fixed costs it can be shown that venturebacked firms emerge in equilibrium if and only if $v_{I V}-F_{I}<v_{V}-F_{V}$. The equilibrium ownership is then illustrated in Figure 5.1. To proceed, define the Preemption-condition as combinations of fixed costs such that the incentive for incumbents to preempt venture capitalists from obtaining the basic innovations, $v_{I V}>v_{V}$, is balanced by a fixed-cost advantage for venture capitalists:

$$
\mathcal{F}_{I}^{P E}\left(F_{V}\right)=\left\{\begin{array}{cl}
F_{V}+v_{I V}-v_{V} ; & F_{V}\left[0, v_{V}\right), \\
v_{V} ; & F_{V} \geq v_{V} .
\end{array} .\right.
$$

Then, define the VC-condition $\mathcal{F}_{I}^{V C}\left(F_{V}\right)$ as combinations of fixed-costs at which a venture capitalist's stronger incentive to aggressively invest in development (to maximize incumbents' willingness to pay in stage 3$), v_{V}>v_{I I}$, is balanced by a fixed-cost disadvantage:

$$
\mathcal{F}_{I}^{V C}\left(F_{V}\right)=\left\{\begin{array}{cc}
0 ; & F_{V} \in\left[0, v_{V}-v_{I I}\right) \\
F_{V}-\left(v_{V}-v_{I I}\right) ; & F_{V} \in\left[0, v_{V}-v_{I I}\right) \\
{\left[v_{I I}, \infty\right) ;} & F_{V}=v_{V}
\end{array}\right.
$$

For relatively high fixed costs for incumbents $F_{I} \geq \mathcal{F}_{I}^{P E}$ in Region 1, the Nash-equilibrium involves a venture capitalist buying the basic innovation at price $S^{B^{*}}=v_{V}-F_{V}$ investing $k_{V}^{*}$ in development. When fixed costs of incumbent firms and venture capitalists are of similar size, i.e. for $F_{I}^{V C}\left(F_{V}\right) \leq F_{I} \leq F_{I}^{P E}$ in Region 2, an incumbent firm obtains the innovation at $S^{B^{*}}=v_{V}-F_{V}$ investing $k_{A}^{*}$ into development. For relatively high fixed costs for venture capitalists in Region 3, an incumbent will acquire the basic innovation at price $S^{B}=v_{I I}-F_{I}$, once more investing $k_{A}^{*}$ in development. Finally, in region 4 in Figure 5.1, no sale of the basic innovation occurs.

Then, by making use of Proposition 2, we can state the following result:

Proposition 4. To be active in equilibrium, venture capitalists must be sufficiently more efficient than incumbent firms in identifying and developing basic innovations into commercialized innovations. 
Proposition 4 provides a possible explanation why venture-backed firms are observed to be more aggressive and more successful in bringing commercialized innovations to the market than incumbent firms. In Figure 5.1, venture-backed firms only appear above the Preemption condition $F_{I}^{P E}\left(F_{V}\right)$. Thus, venture capitalists must be substantially more efficient to exist in equilibrium, since a marginal advantage (i.e. a combination of fixed costs just above the 45 degree line) is not sufficient, as incumbents will then preempt venture capitalists by acquiring basic innovations. ${ }^{22}$

We can also use this set-up to study the impact of the efficiency level of the venture capital industry on the equilibrium innovation and development levels. It is then possible to derive the following result:

Proposition 5. (i) The industrial organization with sufficiently inefficient venture capitalists leads to the lowest level of innovations and development, and (ii) the industrial organization with sufficiently efficient venture capitalists leads to the highest level of innovations and development.

To see this, consider an Industry 1 with $F_{V}=0$ and $F_{I}=v_{I V}$ and an Industry 2 with $F_{V}=v_{V}$ and $F_{I}=0$. These industries are marked out as I1 and I2 in Figure 5.1 , respectively. In stage 1 , only venture capital can provide financing for innovations in Industry 1, whereas only direct incumbent acquisitions occur in Industry 2. In each industry, equilibrium fixed costs are zero, i.e. $F^{*}=0$, leading to an acquisition price for basic innovations of $S_{I 1}^{B^{*}}=v_{V}$ in Industry 1 and $S_{I 2}^{B^{*}}=v_{I I}$ in Industry 2. Thus, from Propositions 1 and 2(i), it then follows that the industry with venture financing does not only generate a higher acquisition price for basic innovations stimulating more innovations, but also more developed innovations. Once more, this occurs as a venture capitalist

\footnotetext{
${ }^{22}$ For simplicity, we have modelled efficiency advantages through the fixed costs. However, the incentives for preemptive acquisitions by incumbents would extend beyond this simple framework. In a more general setting, it follows that venture capital would need to possess substantial advantages in terms of lower variable investments costs, informational advantages, or specific skills to be active in equilibrium.
} 
internalizes the market rivalry among incumbent firms when investing in development, since such investments are guided by a maximization of the net acquisition price in the auction of the developed innovation in stage 3.

On a final note, it has been acknowledged in the literature that entrepreneurs often puts a high value on controlling the development of her initial innovation, and that this control rights would be larger when being financed by a venture capitalist, than acquired by an incumbent. Indeed, if this is the case we might even consider negative values of $F_{V}$ in Figure 5.1. This would then imply that we more likely end up in region 1, with venture-backed entrepreneurial firms.

\section{Extensions}

We have shown that venture capitalists will overinvest in development in order to extract a high sales price for developed innovations and explored the implications of this result. In this section, we examine if the overinvestment mechanism will persists when relaxing some of the simplifying assumption made. In section 6.1 , we examine a model where the entrepreneur and the venture capitalists make simultaneous investments into the venture backed firm, and in section 6.2 , we examine a setting with incumbents being ex-ante asymmetric.

\subsection{Simultaneous investment by the entrepreneur and the venture capitalist}

For simplicity, we have assumed all investments into the venture-backed firm is performed by the venture capitalist. However, in practise, both the entrepreneur and the venture capitalist would often need to invest into the venture. As shown in recent work by Inderst and Mueller (2004) and Hellmann (2006) this may give rise to under-investments due to a double moral hazard problem.

To incorporate this aspect into our framework we now modify stage 1 and 2 of the model keeping the other parts of the model intact. The entrepreneur still need to invest in 
effort to create the basic innovation in stage 0 . In period 1, we then assume that venture capitalist make bids in terms of simple equity-finance contracts $\left\{\alpha, I_{V}\right\}$, specifying the level of initial financing in the project $I_{V}$ and the equity share of the proceeds to the venture capitalist $\alpha \in[0,1]$ when the developed innovation is sold in stage 3 . In period 2 , both agents will now need to simultaneously supply non-contractible investments in the venture-backed firm $k_{E}$ and $k_{V}$ respectively to develop the basic innovation. We solve stage 2 and 3 backwards, keeping in mind that the analysis for the remaining part of the model is as stated above.

\section{Stage 2: Investments}

Let the reduced-form product market profits of the acquirer and a non-acquirer be $R_{A}\left(k_{E}, k_{V}\right)$ and $R_{N A}\left(k_{E}, k_{V}\right)$. Since the price of a developed innovation in stage 3 is $S^{D}=R_{A}\left(k_{E}, k_{V}\right)-R_{N A}\left(k_{E}, k_{V}\right)$, the net profit of the entrepreneur is $(1-\alpha) S^{D}-C\left(k_{E}\right)$, whereas the net profit for the venture capitalist is $\alpha S^{D}-C\left(k_{V}\right)$. The optimal investments are then given from (3.7), which now takes the form:

$$
\alpha\left[\frac{d R_{A}}{d k_{V}}-\frac{d R_{N A}}{d k_{V}}\right]=C^{\prime}\left(k_{V}^{*}\right), \quad(1-\alpha)\left[\frac{d R_{A}}{d k_{E}}-\frac{d R_{N A}}{d k_{E}}\right]=C^{\prime}\left(k_{E}^{*}\right) .
$$

Under a direct acquisition, the acquiring incumbent firm set $k_{A}$ and $\tilde{k}_{E}$ to maximize profit, where $k_{A}$ correspond to the venture capitalists investment $k_{V}$, and $\tilde{k}_{E}$ to the entrepreneurs investment $k_{E}$. The optimal investments are given from (3.5), which now take the form:

$$
\frac{d R_{A}}{d k_{A}}=C^{\prime}\left(k_{A}^{*}\right), \quad \frac{d R_{A}}{d k_{E}}=C^{\prime}\left(\tilde{k}_{E}^{*}\right)
$$

The entrepreneur and the incumbent (or its employees) are rewarded according to their full marginal products. Thus, as a benchmark, we assume that there is no double moral hazard problem under a direct acquisition by an incumbent.

Comparing (6.1) and (6.2), we see that the incentives for strategic overinvestment effect is still present, since the entrepreneur and venture capitalist achieves a higher acquisition price by not only taking into account the increase in profits for the acquirer, but also by 
exploiting the negative externalities on the non-acquirer. However, in (6.1) there is a also free riding problem present in that the entrepreneur and venture capitalist only take into account their share of the increase in profit when investing, while ignoring the positive effect on the collaborator in the venture.

\section{Stage 1: The equity-finance contract}

We here study the property of the equity-finance contract and its effects on the investments. To this end, let $W$ be the wealth of the entrepreneur and $F_{V}$ be the fixed cost of investments required in period 1 to undertake the venture. The bidding competition among venture capitalists implies that a winning equity-finance contract $\left\{\alpha, I_{V}\right\}$ must imply that the venture capitalist will make a zero profit: $I_{V}(\alpha)=\alpha S^{D}(\alpha)-C\left(k_{V}^{*}(\alpha)\right)$, where $S^{D}(\alpha)=R_{A}\left(k_{V}^{*}(\alpha), k_{E}^{*}(\alpha)\right)-R_{N A}\left(\left(k_{V}^{*}(\alpha), k_{E}^{*}(\alpha)\right)\right.$ is the sales price of a developed innovation in stage 3. Moreover, the competition between the venture-capitalists implies that the winning contract will give the entrepreneur the highest gain possible given that the venture capitalist breaks even. To find such a contract we may first note that the entrepreneur's net profits is $(1-\alpha) S^{D}(\alpha)-C\left(k_{E}^{*}(\alpha)\right)-F_{V}+I_{V}$. Inserting the equilibrium financing level by the venture capitalist $I_{V}(\alpha)$ into the entrepreneurs net profits, gives the following maximization problem:

$$
\begin{array}{ll} 
& \operatorname{Max}_{\{\alpha\}}: S^{D}(\alpha)-C\left(k_{E}^{*}(\alpha)\right)-C\left(k_{V}^{*}(\alpha)\right)-F_{V} \\
\text { s.t }: & I_{V}(\alpha) \geq F_{V}-W
\end{array}
$$

There are two possible solution to this maximization problem, depending on the wealth constraint is binding or not.

Case (a): The entrepreneur is not wealth constrained If the wealth constraint is not binding, the optimal equity share $\alpha^{*}$ is:

$$
\alpha^{*}=\arg \max : S^{D}(\alpha)-C\left(k_{E}^{*}(\alpha)\right)-C\left(k_{V}^{*}(\alpha)\right)-F_{V}
$$


with $I_{V}^{*}$ given from $I_{V}\left(\alpha^{*}\right)=\alpha^{*} S^{D}\left(\alpha^{*}\right)-C\left(k_{V}^{*}\left(\alpha^{*}\right)\right)>F-W$. Using (6.4) in (6.1), we can obtain the optimal investments $k_{V}^{*}\left(\alpha^{*}\right)$ and $k_{E}^{*}\left(\alpha^{*}\right)$ in the venture-backed firms which can now be compared to the investments $k_{A}^{*}$ and $\tilde{k}_{E}^{*}$ under a direct acquisition by an incumbent from (6.2).

To obtain more specific results, we apply a Linear-Quadratic Cournot model (LQC). The product market competition in stage 4 is then a Cournot-duopoly in homogeneous goods with linear demand, $P=a-\frac{Q}{s}$, where $a$ indicates consumer willingness to pay and $s$ denotes market size. Direct product market profits are $\Pi_{h}=\left(P-c_{h}\right) x_{h}$, where $x_{h}$ is the output for a firm of type $h=\{A, N A\}$. The marginal cost of the acquirer is $c_{A}=c-\left[\theta k_{A}+\tilde{k}_{E}\right]$ under direct acquisition by an incumbent, and $c_{A}=c-\left[\theta k_{V}+k_{E}\right]$ when development is undertaken by the venture-backed firm. For simplicity, we will assume that the entrepreneur is at least as efficient as the venture capitalist in development. To this end, the parameter $\theta$, which captures the importance of the entrepreneur for the development of the innovation, is in the interval $[0,1]$. The non-acquirer is assumed to have the marginal cost $c_{N A}=c$. Reduced-form profits in (3.2) then take the form $R_{h}=\frac{1}{s}\left(q_{h}^{*}\right)^{2}$, where $q_{h}^{*}=s \frac{a-2 c_{h}+c_{-h}}{3}$. Total investment cost for development faced by each type of investor, $t=A, V$ are $C\left(k_{t}\right)=\frac{\mu k_{t}^{2}}{2}+F_{t}$.

Let the difference in optimal total investment levels between the venture backed firm and the incumbent firm be $K_{V}^{*}\left(\alpha^{*}\right)-K_{A}^{*}=\theta k_{V}^{*}\left(\alpha^{*}\right)+k_{E}^{*}\left(\alpha^{*}\right)-\left[\theta k_{A}^{*}+\tilde{k}_{E}^{*}\right]$. We then have the following proposition:

Proposition 6. In the LQC-model, if the entrepreneur is not wealth constrained, the optimal total level of development by a venture-backed firm, which resells the developed innovation to an incumbent firm, exceeds the optimal total level of development by the acquiring incumbent firm, $K_{V}^{*}>K_{A}^{*}$, if and only if the entrepreneur is sufficiently efficient developing the basic innovation, i.e. if $\theta \in[0, \bar{\theta})$ for $\bar{\theta}<1$.

Proof. See, the Appendix.

When the entrepreneur is important for developing the basic innovation ( $\theta$ is low), 
the optimal equity contract assigns a large share of the proceeds to the entrepreneur $\left(\alpha^{*}\right.$ small). This reduces the moral hazard problem and the over-investment effect dominates the under-investment effect. However, when the entrepreneur and the venture capitalist become more symmetric, the under-investment problem dominates. This is illustrated in Figures 6.1(i) and (ii).

Case (b): The entrepreneur is wealth constrained In this case the optimal contract $\alpha^{*}$ implies that the funding requirement faced by the entrepreneur's venture cannot be covered. Thus, if $I_{V}\left(\alpha^{*}\right)<F-w$ holds, the equity contract $\hat{\alpha}$ must be derived from the constraint $I_{V}(\hat{\alpha})=F-w$, or:

$$
\hat{\alpha} S^{D}(\hat{\alpha})-C\left(k_{V}^{*}(\hat{\alpha})\right)=F-w
$$

Using (6.1) and (6.5), we can obtain optimal investments $k_{V}^{*}(\hat{\alpha})$ and $k_{E}^{*}(\hat{\alpha})$, which can again be compared with $k_{A}^{*}$ and $\tilde{k}_{E}^{*}$ under a direct acquisition by an incumbent. As illustrated in Figure Y (iv), when the entrepreneur is wealth constrained, we have $\hat{\alpha}>\alpha^{*}$. Intuitively, in order to receive sufficient financing from venture capitalist covering the funding requirement $F-w$, the entrepreneur needs to increase the equity share to the venture capitalist above the efficient contract $\alpha^{*}$. As shown by the numerical example in Figure 6.1(iii) and (iv), which again applies the LQC-model, this tend to limit, but not eliminate the strategic overinvests, in the venture-backed firm. ${ }^{23}$

We have thus shown that over investments can occur also under simultaneous investments. This implies that there will again be an incentive for preemptive acquisitions of basic innovations by incumbent firms, and venture-backed firms will exist in equilibrium if and only if $v_{I V}-F_{I}<v_{V}-F_{V}$, as previously shown in Section $5 .^{24}$

We should also note that we have ignored the potential moral hazard problem between

\footnotetext{
${ }^{23}$ For the parameter values used in Figure 6.1, see the Appendix.

${ }^{24}$ Hellmann (2006) and Schmidt (2003) show that if the venture backed firm also could exit by an IPO a convertible preferred equity contract would be optimal. However, allowing also IPOs is outside the scope of this paper.
} 


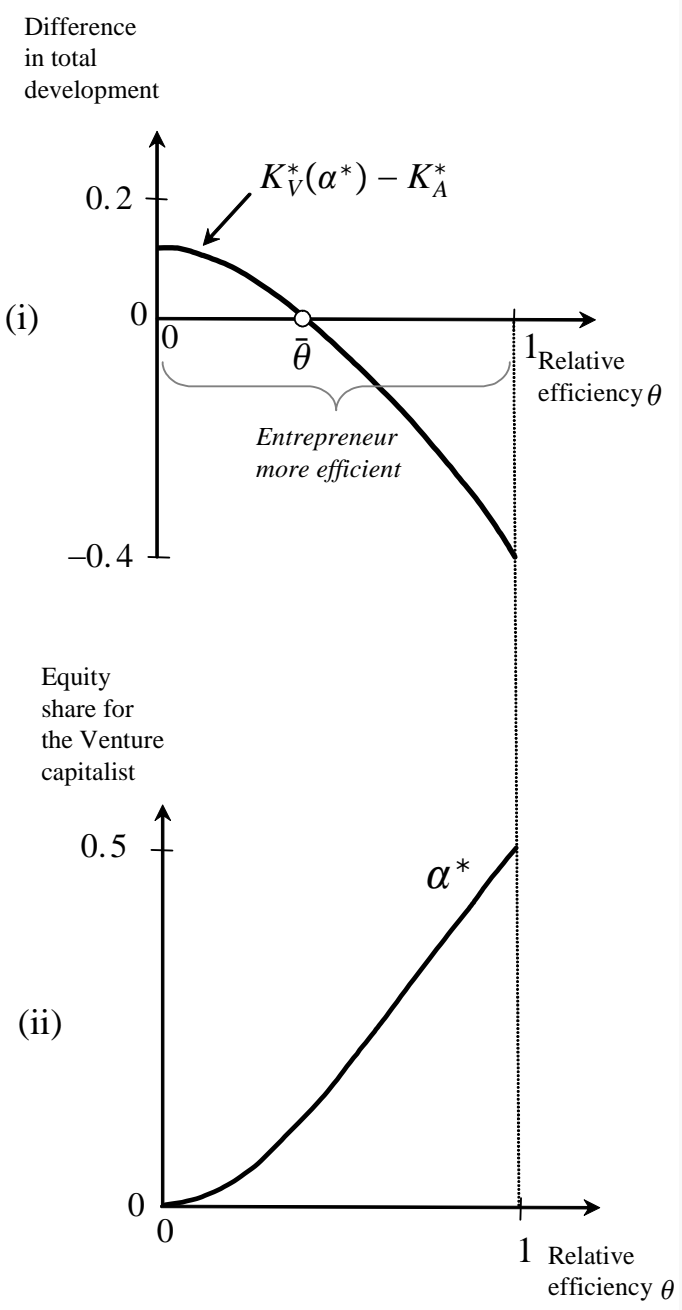

Case (a): The entrepreneur is not wealth constrained

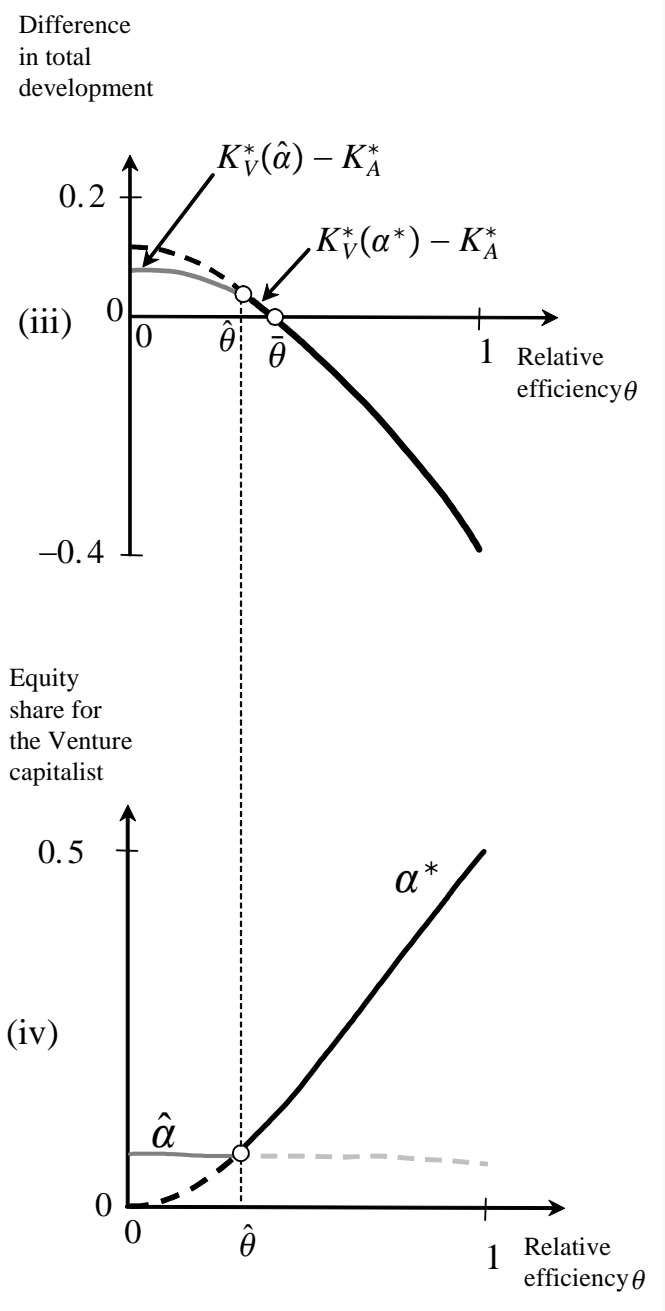

Case (b): The entrepreneur is wealth constrained

Figure 6.1: Simultaneous investment by the entrepreneur and the venture capitalist in the Linear-Qudratic model. 
the employees (possibly including the entrepreneur) in an incumbent firm under a direct acquisition. If this problem is similar in size or larger than the between the entrepreneur and the venture capitalist then overinvestment will always take place in equilibrium.

\subsection{Overinvestment with asymmetric incumbents}

In this extension, we examine if overinvestment by venture capitalist also can emerge when relaxing the assumption of incumbents being symmetric ex-ante.

Consider the LQC model and assume that the industry contains a large incumbent (L) and a small incumbent (S). Let $i, j=\{L, S\}$ denote firm index. The reduced-form profits for firm $i$ when firm $j$ has obtained the developed innovation is $R_{i j}=\frac{1}{s}\left(q_{i j}^{*}\right)^{2}$, where $q_{i j}^{*}=s \frac{a-2 c_{i j}+c_{-i j}}{3}$. Let $c_{i j}=\bar{c}_{i}$ for $i \neq j$ and $c_{i i}=\bar{c}_{i}-\theta_{i} k$ is the marginal cost for $i$ when not possessing the innovation and possessing the innovation, respectively. To capture ex-ante differences in size, we assume that $\bar{c}_{L}<\bar{c}_{S}$, which may be thought of stronger firm-specific assets accumulated in the large firm L. Explicit expressions for $q_{i j}^{*}$ are given in (B.5) in the Appendix.

It is useful to note that firm $i$ 's valuation in stage 3 for a developed innovation in (3.3) is $w_{i j}=R_{i i}-R_{i j}$ for $i \neq j$. Differentiation of $w_{i j}$ in $k$ yields:

$$
\begin{aligned}
& \frac{d w_{L S}}{d k}=R_{L L}^{\prime}-R_{L S}^{\prime}=\frac{4}{3} \theta_{L} q_{L L}^{*}+\frac{1}{3} \theta_{S} q_{L S}^{*} \\
& \frac{d w_{S L}}{d k}=R_{S S}^{\prime}-R_{S L}^{\prime}=\frac{4}{3} \theta_{S} q_{S S}^{*}+\frac{1}{3} \theta_{L} q_{S L}^{*}
\end{aligned}
$$

As shown in the Appendix, if the large and the small firm are equally efficient in using the developed innovation, $\theta_{L}=\theta_{S}=\theta$, the larger firm will have a higher valuation $w_{L S}>w_{S L}$. Intuitively, from (6.6) and (6.7), the increase in profit induced from developing the innovation affects more units in the large firm when this firm obtains the innovation, $q_{L L}^{*}>q_{S S}^{*}$. At the same time, the loss in profit as non-acquirer is more severe for the large firm, since the reduction in profit also affects more units, $q_{L S}^{*}>q_{S L}^{*}$. Therefore, $\frac{d w_{L S}}{d k}>$ $\frac{d w_{S L}}{d k}$ will hold for a positive development level $k$. Since, by defintion, $w_{L S}=w_{S L}=0$ at $k=0, w_{L S}>w_{S L}$ must hold for $k>0$. Thus, when firms are equally efficient in 
developing innovations, the larger firm will have a higher valuation for developed assets due to its size.

We can now discuss overinvestment in this setting. Since the acquisition price in stage 1 will be $S^{B^{*}}=w_{S L}$, a venture capitalist will maximize the net valuation of the small firm $w_{S L}-C(k)$, choosing $k_{V}^{*}=\arg \max _{k} w_{S L}(k)-C(k)$. This implies that the incentive for overinvestment is reduced, and there might be under investment in the venture-backed firm as compared to the optimal investment under a direct acquisition by the large incumbent, $k_{L}^{*}=\arg \max _{k} R_{L L}(k)-C(k)$. Under-investment in the venture-backed firm, $k_{V}^{*}<k_{L}^{*}$, would thus occur if $R_{L L}^{\prime}>w_{S L}^{\prime}=R_{S S}^{\prime}-R_{S L}^{\prime}$. As shown in the Appendix, this arises if the ex-ante difference in marginal $\operatorname{costs} \bar{c}_{S}-\bar{c}_{L}>0$ of the two firms is sufficiently large. However, if this ex-ante difference is not too large there will be overinvestement in the venture-backed firm, $k_{V}^{*}>k_{L}^{*}$. Thus, overinvestment may also arise in a setting with assymetric incumbents.

\section{Empirical implications}

In the presentation, we have pointed to several examples where the theory is consistent with empirical findings. On a more general level, Kortum and Lerner (2000) find that presence of venture capitalists significantly increases patenting rates in US-industries, noting that while the size of venture capital is less than $3 \%$ of corporate R\&D outlays, Venture capital account for about $8 \%$ of industrial innovations. Our model predicts such an efficiency effect of Venture capital (Proposition 5) stemming from three interrelated mechanisms.

First, venture capitalists develop innovations more aggressively, since the sales price of an innovation - rather than the product market profit - is maximized. Second, since part of the increase in the sales price is generated by exploiting the negative externalities on non-acquiring incumbents, venture capitalists also need to be more efficient to exist in equilibrium. Third, venture capitalists also act as a potential threat to incumbents, which will increase the rewards to innovation. 
Let us now discuss some additional testable implications of the model. One way to test the over-investment effect (Proposition 1) would be to directly compare firm level data on devlopment $k_{V}^{*}$ and $k_{A}^{*}$ (or their costs $C\left(k_{V}^{*}\right)$ and $C\left(k_{A}^{*}\right)$ ) for innovations held by venturebacked firms and incumbent firms, respectively. Due to the problem of measurement and availability for such detailed data an alternative method would be to use stockmarket data to test the over-investment effect indirectly. The model's stock market predictions will of course be sensitive to how and when the information about the progress and potential of the venture reaches the stockmarket. Keeping this in mind, suppose that the stock market is efficient. That is, the stock market values firms according to their expected profits, and understands the structure of the game in Figure 2.1, in terms of the innovation decision, acquisition game, development decisions and the subsequent product market interaction in stages 0-4. Moreover, to highlight the effect of the emergence of venture-backed firms, assume that the level of fixed cost associated with the development of the basic innovation stage 1 is not perfectly known, so that the outcome of the acquisition game in stage 1 will come as partial surprise for the stock market.

Under these assumptions, the model would predict that the stockmarket value of incumbents would decrease around the announcement of the signing of a contract between an entrepreneur and venture capitalist of an important venture. The reason being that the stockmarket then foresees a more aggressive development of the innovation than previously expected, and that this will hurt incumbents in the subsequent acquisition process and product market interaction. Formally, we noted this in (4.5), which showed the inequality $R_{A}\left(k_{A}^{*}\right)>\pi_{A}^{*}>R_{N A}\left(k_{V}^{*}\right)$, where $\pi_{A}^{*}$ is the net profit for an incumbent buying the basic innovation, $R_{A}\left(k_{A}^{*}\right)$ is the net profit of the non buying incumbents, and $R_{N A}\left(k_{V}^{*}\right)$ is the net profit for incumbents if development takes place in the venture backed firm. Thus, the subsequent over-investment by the venture-backed firm will reduce the profits of all incumbents, including the acquirer.

In addition, assuming that the identity of the buyer in the case of a preemptive acquisition in period 1 comes as a surprise for the stock market, a second prediction from 
(4.5) would be that the stockmarket value of the non-acquring incumbents would do better than the acquiring incumbent's stock market value when a preemptive early acquisition (or incumbent financing of a venture) is announced. This follows from $R_{A}\left(k_{A}^{*}\right)>\pi_{A}^{*}$, since when a preemptive acquisition occur, the outsiders free-ride on the acquirer and are hence perform better than the acquiring incumbent.

\section{Conclusions}

This paper takes as its starting point that the exit of venture-backed firms often takes place through a sale to an incumbent firm. We show that in such an environment, venturebacked firms have a stronger incentive to develop basic innovations into commercialized innovations than do incumbent firms, due to strategic product market effects on the sales price of the venture-backed firm. In turn, this will increase the price for basic innovations, thereby triggering more basic innovations by entrepreneurs.

In the previous literature venture capital has been shown to play an important role in the innovation market by supporting entrepreneurs to create new firms. We here identify another important role of venture capital: in situations where entrepreneurs sell innovations to existing incumbents, venture capital support entrepreneurs to participate in the development process of an innovation to a larger extent, which implies that the innovations developed closer to its full potential. This occurs because independent venture-backed firms develop innovations more aggressively than incumbent firms in order to extract a high sales price.

The model also provides a potential explanation why venture-backed firms are observed to be more efficient in bringing commercialized innovations to the market than incumbent firms. Empirical research on venture capitalists suggests that they possess unique assets in terms of informational advantages, monitoring and control abilities and thereby, they are more efficient in bringing commercialized innovations to the market than incumbent firms. However, it might then be believed that less skilled venture capitalists would enter the 
market and reduce this difference in efficiency. Our model provides an explanation why this might not necessarily be the case. The reason is that when innovations will be used in an oligopolistic markets, venture-backed firms will, in equilibrium, produce more development than incumbents due to strategic product market effects. This implies that to exist in equilibrium, venture capitalists must be substantially more efficient than incumbents, otherwise incumbents will preempt venture capitalists by acquiring basic innovations.

Our results thus provide additional support for the policy view that a well-functioning venture capital market will increase the innovative activity in a country. Moreover, our results indicates that the importance of the presence of a venture capital market for innovation activity may be underestimated in empirical work. To see this, note that the presence of venture capitalist as potential independent developers, even if they do not develop innovations in equilibrium, still increases the reward and, hence, the incentives for entrepreneurial innovations,

In the analysis, we have assumed that the seller of the innovation uses a first-price sealed bid auction. We believe that this auction set-up captures essential features of the bidding competition over a scarce asset in situations where acquisitions are used to gain access to innovations, which are indeed frequently used in practice. But this implies that some possibilities for creating additional rents are potentially neglected. More generally, Jehiel, Moldovanu and Stacchettis (1999) show that sophisticated mechanisms are needed to maximize revenues in auctions with externalities where, for instance, it might be the case that all firms in the market need to provide transfers to the seller. However, as pointed out by Jehiel and Moldovanu (2000), a problem with these mechanisms is that the seller needs unrealistically strong commitment power and thus, these mechanisms are often not feasible. ${ }^{25}$ Nevertheless, if more sophisticated selling mechanisms would allocate

\footnotetext{
${ }^{25}$ One potentially feasible strategy which enables venture-backed firms to extract more rents would be to sell the basic innovation, threatening to aggressively develop the innovation. Assuming away fixed development costs, an incumbent firm would be willing to pay $v_{I V}=R_{A}\left(k_{A}^{*}\right)-C\left(k_{A}^{*}\right)-R_{N A}\left(k_{V}^{*}\right)$, which would give the venture-backed firm larger proceeds as compared to the case when it develops the
} 
a larger share of the surplus to the entrpereneur, the existence of a venture capital market would trigger even more basic innovations. The extra payment would also be higher in cases where the entrepreneur could develop the innovation herself.

What would happen if we allowed the venture capitalist to exit also by an initial public offering (IPO), i.e. allowing the venture backed firm to enter the product market? It then follows directly, that if it is more profitable to exit by a sale to an incumbent, our model set-up is valid. Gans et al. (2002) and Gans and Stern (2003) show that firms are more likely to act as suppliers of technology when intellectual property rights are secure, investment costs are high and brokers facilitating trade are available. When the opposite applies, start-ups are more likely to commercialize their innovations through entry. However, also taking into account product market effects, we expect several other variables to be important for this choice, such as the type of innovation: product or process innovation, drastic and non-drastic innovation, the intensity of product market competition and type and strength of information problems. A study of these issue is left to future research.

\section{A. Appendix:}

\section{A.1. Proof of Lemma 1}

First, consider the equilibrium candidate where incumbent $i_{w}$ acquires the innovation, denoted $\mathbf{b}^{*}$. Note that $b_{i_{w}}^{*}>w_{I I}-\varepsilon$ is a weakly dominated strategy, since no owner will innovation and then sells it, since it would then get $w_{I I}-C\left(k_{V}^{*}\right)=R_{A}\left(k_{V}^{*}\right)-C\left(k_{V}^{*}\right)-R_{N A}\left(k_{V}^{*}\right)$, where $w_{I I}-C\left(k_{V}^{*}\right)<v_{I V}$. One way to achieve this would be through stating a reservation price at $v_{I V}$. But this will create problems unless the entrepreneur can develop the innovation herself. To see this if the reservation price is $v_{I V}>v_{V}$ venture capitalists might not want to participate in the auction and the threat of over development might not be credible and thus the maximum willingness to pay for incumbents would then be $v_{I I}$. Thus, the entrepreneur would then be forced to charge a lower reservation price than $v_{I V}$. 
post a bid over its maximum valuation of obtaining the innovation. If $b_{i_{w}}^{*}<w_{I I}-\varepsilon$, firm $\mathrm{i}_{s}$ benefits from deviating to $b_{i_{s}}^{* *}=b_{i_{w}}^{*}+\varepsilon$, since it then obtains the innovation and pays a price lower than its valuation of obtaining it. Last, consider candidate $b_{i_{w}}^{*}=w_{I I}-\varepsilon$, $b_{i_{s}}^{*}=w_{I I}-2 \varepsilon$. Then, no owner has an incentive to deviate. Thus, this is a Nash equilibrium and the only NE where firm $i_{w}$ obtains the assets.

Second, note that the situation where no incumbent obtains the innovation cannot occur if there is no reservation price at the auction.

\section{B. The Linear Quadratic Cournot Model}

\section{B.1. Simultaneous investment by the entrepreneur and the venture capitalist}

Applying the Linear-Quadratic Cournot (LQC) model described in Section 6.1 to the FOC in (6.1), we obtain the investments in the venture backed firms:

$$
k_{V}^{*}=\frac{2 \Lambda \alpha \theta}{2 \alpha+3 \mu-2 \theta^{2} \alpha-2}, \quad k_{E}^{*}=\frac{2(1-\alpha) \Lambda}{2 \alpha+3 \mu-2 \theta^{2} \alpha-2},
$$

Assuming that the Second-Order condition (SOC) for the venture capitalist $3 \mu-2 \theta^{2} \alpha>0$, the SOC for the entrepreneur $2 \alpha+3 \mu-2>0$ and the stability condition $2 \alpha-2 \theta^{2} \alpha+3 \mu-2>$ 0 are fulfilled, (B.1) is a unique, stable Nash-equilibrium.

Applying the LQC model to the FOC (6.2), we obtain the investments in the incumbent firm:

$$
k_{A}^{*}=\frac{4 \Lambda \theta}{9 \mu-8 \theta^{2}-8}, \quad \tilde{k}_{E}=\frac{4 \Lambda}{9 \mu-8 \theta^{2}-8}
$$

Likewise, assuming that the SOC for the Incumbent $9 \mu-8 \theta^{2}>0$, the SOC for the entreprenenur $9 \mu-8>0$ and the stability condition $9 \mu-8 \theta^{2}-8$ are fulfilled, (B.2) is a unique, stable Nash-equilibrium.

\section{B.1.1. Proof of Proposition 6}

Using (B.1), it can be shown that the optimal equity contract in (6.4) is: 


$$
\alpha^{*}=\frac{(3 \mu-2) \theta^{2}}{3 \mu-4 \theta^{2}+3 \theta^{2} \mu}>0
$$

with associated the second-order condtion $-4 \frac{\left(3 \mu-2 \theta^{2}\right)\left(3 \mu-4 \theta^{2}+3 \theta^{2} \mu\right)^{4}}{\left(\theta^{2}+1\right)^{-3}\left(3 \mu-2 \theta^{2}\right)^{4}(3 \mu-2)^{3}} \mu \Lambda^{2}<0$, where $3 \mu-$ $2 \theta^{2} \alpha>0$ is the SOC for the Venture capitalist, which also implies that $3 \mu-2>0$ since $\theta, \alpha \in[0,1]$. The latter condition $3 \mu-2>0$ and the SOC for Incumbent $9 \mu-8 \theta^{2}>0$ ensures $3 \mu-4 \theta^{2}+3 \theta^{2} \mu>0$ and, hence, $\alpha^{*}>0$, wheras the SOC for the Venture capitalist $3 \mu-2 \theta^{2} \alpha>0$ ensures $\alpha^{*}<1$.Using (B.1)-(B.3) in $K_{V}^{*}\left(\alpha^{*}\right)-K_{A}^{*}=\theta k_{V}^{*}\left(\alpha^{*}\right)+k_{E}^{*}\left(\alpha^{*}\right)-$ $\left[\theta k_{A}^{*}+\tilde{k}_{E}^{*}\right]$ and evaluating at $\theta=0$ and $\theta=1$, we then obtain:

$$
\begin{aligned}
& \left.K^{V C}\right|_{\theta=0}-\left.K^{I n c}\right|_{\theta=0}=2 \Lambda \frac{3 \mu-4}{(3 \mu-2)(9 \mu-8)}>0 \\
& \left.K^{V C}\right|_{\theta=1}-\left.K^{I n c}\right|_{\theta=1}=-2 \Lambda \frac{3 \mu+8}{(3 \mu-2)(9 \mu-16)}<0
\end{aligned}
$$

In (B.4) $9 \mu-16>0$ follows from the stability of (B.2), while $3 \mu-4>0$ needs to hold in order to have $\left.q_{N A}\left(K_{A}^{*}\right)\right|_{\theta=0}=\frac{3 \mu-4}{9 \mu-8} \Lambda>0$. Since $K_{V}^{*}\left(\alpha^{*}\right)-K_{A}^{*}$ is continious in $\theta$, it follows from (B.4) that there must then exist at $\bar{\theta} \in(0,1)$ such that $\left.K^{V C}\right|_{\theta=\bar{\theta}}-\left.K^{I n c}\right|_{\theta=\bar{\theta}}=0$. As illusttration, Figure 6.1(i) and (ii) are drawn for $\mu=4, \Lambda=a-c=2$, and $F_{V}-W=x$. Figure 6.1(iii) and (iiv) are drawn for $\mu=4, \Lambda=a-c=2$, and $F_{V}-W=y$.

\section{B.2. Overinvestment with asymmetric incumbents}

Applying the Linear-Quadratic Cournot (LQC) model described in Section 6.2 to the FOC in (3.1), we obtain:

$$
q_{L L}^{*}=s \frac{a+2 \theta_{L} k+\bar{c}_{S}-\bar{c}_{L}}{3}, q_{S S}^{*}=s \frac{a+2 \theta_{S} k+\bar{c}_{L}-\bar{c}_{S}}{3}, q_{L S}^{*}=s \frac{a-\theta_{S} k+\bar{c}_{S}-\bar{c}_{L}}{3}, q_{S L}^{*}=s \frac{a-\theta_{L} k+\bar{c}_{L}-\bar{c}_{S}}{3} .
$$

From (B.5), we note that $q_{L L}^{*}>q_{S S}^{*}$ and $q_{L S}^{*}>q_{S L}^{*}$ holds when $\theta_{S}=\theta_{L}$ under the assumption $\bar{c}_{S}-\bar{c}_{L}>0$.

Moreover, $k_{V}^{*}=\arg \max _{k} w_{S L}(k)-C(k)$ and $k_{L}^{*}=\arg \max _{k} R_{L L}(k)-C(k)$. Thus, $k_{V}^{*}=k_{L}^{*}$ holds if $R_{L L}^{\prime}=w_{S L}^{\prime}=R_{S S}^{\prime}-R_{S L}^{\prime}$. From (6.6)-(6.7), we have $R_{L L}^{\prime}=\frac{4}{3} \theta_{L} q_{L L}^{*}$ and 
$R_{S S}^{\prime}-R_{S L}^{\prime}=\frac{4}{3} \theta_{S} q_{S S}^{*}+\frac{1}{3} \theta_{L} q_{S L}^{*}$. Subsitituting (B.5) into these expressions and solving for the critical exante difference $\Delta c=\bar{c}_{S}-\bar{c}_{L}$ for which $R_{L L}^{\prime}=R_{S S}^{\prime}-R_{S L}^{\prime}$, we obtain:

$$
\Delta c=\frac{\left(4 \theta_{S}-3 \theta_{L}\right) a+\left(8 \theta_{S}^{2}-9 \theta_{L}^{2}\right) k}{4 \theta_{S}+5 \theta_{L}}
$$

In the case where $\theta_{S}=\theta_{L}=\theta, \Delta c=\frac{a-\theta k}{9}>0$. We then have underinvestment in the venture-backed firm $\left(k_{V}^{*}<k_{L}^{*}\right)$ if the exante cost difference is sufficently large, $\bar{c}_{S}-\bar{c}_{L}>\Delta c$,

but overinvestment $\left(k_{V}^{*}>k_{L}^{*}\right)$ if the exante cost differenceis sufficiently low, $0<\bar{c}_{S}-\bar{c}_{L}<$ $\Delta c$. Finally, note that if there is an ex-post advantage of the smaller firm $\theta_{S}>\theta_{L}$, an even larger exante difference $\Delta c$ is required to generate underinvestment in the venture-backed firm.

\section{References}

[1] Acs, Z. J. and Audretsch D. B., 2005, "Entrepreneurship, Innovation and Technological Change," Foundations and Trends in Entrepreuneurship, Vol 1, No 4, 149-195.

[2] Amador, M. and Landier, A., 2003, "Entrepreneurial Pressure and Innovation". Available at SSRN: http://ssrn.com/abstract $=436320$.

[3] Anand, B. N, Galetovic A., and Stein A., 2004, Incentives versus synergies in markets for talent, Available at SSRN: http://ssrn.com/abstract=513042.

[4] Anton, J. J. and Yao D. A., 1994, Expropriation and Inventions: Appropriable rents in the abscence of property rights, American Economic Review, Vol. 84, No. 1, 190-209.

[5] Baumol W. J., 2002, The free-market innovation machine, Princeton university press, New Jersey.

[6] Baumol W. J., 2004, Entrepreneurial Enterprises, Large Established Firms and Other Components of the Free-Market Growth Machine," Small Business Economics, Volume 23, Number 1, 9 - 21. 
[7] Bianch, M. and Henrekson M., 2005, "Is Neoclassical Economics Still Entrepreneurless?", Kyklos, Vol. 58, No. 3.

[8] Bottazzi, L. and Da Rin, M., 2002, "Venture Capital in Europe and the financing of innovative companies," Economic Policy, vol. 34, 229-269.

[9] Bottazzi, L., Da Rin, M., and Hellmann, T., 2004, "The changing face of the European venture capital industry:facts and analysis," Journal of Private Equity, vol. 8, n.1.

[10] Chen, Y., 2000, Strategic Bidding by Potential Competitors: Will Monopoly Persist?, "Journal of Industrial Economics," v48, n2, 161-75.

[11] Cochrane J. H., 2005, "The risk and Return of Venture Capital", Journal of Financial Economics, Vol., Issue 1, Pages 3-52.

[12] Cumming, D. J., MacIntosh, J. G., 2003, "A cross-country comparison of full and partial venture capital exits," Journal of Banking and Finance, 27, pp. 511-548.

[13] European Commission, 1999. Risk Capital Markets, a key to Job Creation in Europe. From Fragmentation to Integration, Euro Papers No. 32, 1-36.

[14] Farrell, J and Shapiro, C, 1990, "Asset Ownership and Market Structure in Oligopoly," RAND Journal of Economics, Vol. 21, 275-292.

[15] Gans, J.S., D.H. Hsu, S. Stern (2002), "When does Start-Up Innovation Spur the Gale of Creative Destruction?", RAND Journal of Economics vol. 33:4, 571-586.

[16] Gans, J.S. and S. Stern, 2000, "Incumbency and R\&D Incentives: Licensing the Gale of Creative Destruction," Journal of Economics and Management Strategy, Vol.9, No.4, pp.485-511.

[17] Gans, J.S. and S. Stern, 2003, "The Product Market and the Market for "Ideas": Commercialization Strategies for Technology Entrepreneurs", Research Policy vol. $32: 2,333-350$. 
[18] Gilbert, .R., and D.M.G., Newbery, 1982, "Preemptive Patenting and the Persistence of Monopoly", American Economic Review, v72, n3 : 514-26

[19] Gompers, P., and Lerner, J., 2001, "The venture Capital Revolution," Journal of Economic Perspective, no. 2, pp. 145-168.

[20] Granstrand, O. and S. Sjölander (1990), "The Acquisition of Technology and Small Firms by Large Firms", Journal of Economic Behavior and Organization vol. 13, $367-386$.

[21] Gromb, D. and Scharfstein D., 2002, "Entreprenuership in equilibrium", NBER Working Paper 9001.

[22] Hellman, T , 2002, "A theory of strategic venture investing," Journal of Financial Economics, 64, 285-314.

[23] Hellmann, T, 2006, "IPOs, Acquisitions and the use of convertible securities in venture capital, Journal of Financial Economics, 81, 649-679.

[24] Hellman, T. and Puri M., 2000, "The Interaction Between Product Market and Financing Strategy: The role of venture capital," Review of Financial Studies, Vol. 13, No. 4, pp. 959-984.

[25] Hellman, T. and Puri M, 2002, "Venture Capital and the Professionalization of Startup Firms: Empirical Evidence", The Journal of Finance, Vol. 57, No. 1, pp. 169-197.

[26] Inderst, R. and Muller, H., 2004, "The effect of capital market characteristics on the value of start-up firms," Journal of Financial Economics, 72, 319-356.

[27] Jehiel, P. and Moldovanu, B., 2000, "Auctions with Downstream Interaction among Buyers", RAND Journal of Economics, v31, n4 : 768-91.

[28] Jehiel, P., Moldovanu, B., and Stacchetti, E., 1999, "Multidimensional Mechanism design for auctions with externalities," Journal of Economic Theory, 85, 258-293. 
[29] Kamien, M.I., 1992, "Patent Licensing", Handbook of game theory with economic applications. Volume 1: 331-54 North-Holland; New York.

[30] Katz, M. L. and Shapiro C, 1996, "How to licence intangible property", Quarterly Journal of Economics,

[31] Keuschnigg, C. and Nielsen, S. B, 2004, "Start-Ups, Venture Capitalists, and the Capital Gains Tax", Journal of Public Economics v88, n5 : 1011-42.

[32] Kortum, S. and J. Lerner, 2000, "Assessing the Contribution of Venture Capital to Innovation", RAND Journal of Economics vol. 31, 674-692.

[33] Lerner, J. and R. Merges, 1998, "The Control of Strategic Alliances: an Empirical Analysis of the Biotechnology Industry", Journal of Industrial Economics vol. 46, $125-156$.

[34] Norbäck, P.J., and L. Persson, 2004, "The Organization of the Innovation Industry: Entrepreneurs, Venture Capitalists, and Oligopolists", Working Paper 626, Research Institute of Industrial Economics.

[35] OECD, 1999, OECD Economic Surveys: Austria.

[36] OECD, 2002, OECD Small and Medium Enterprise Outlook, OECD, Paris.

[37] Schmidt, K., 2003, "Convertible securities and venture capital finance," Journal of Finance, 58, 1139-1166.

[38] Venture Impact 2004, Venture Capital Benefits to the U.S. Economy, Global Insight.

[39] Zahra, S. A., 1996, "Technology strategy and new venture performance: a study of corporate-sponsored and independent biotechnology ventures," Journal of Business Venturing", 11, 289-321. 